\title{
Perfil clínico epidemiológico do câncer gástrico: revisão integrativa
}

\author{
Epidemiological clinical profile of gastric cancer: an integrative review
}

\author{
Flávio Souza Gonçalves $^{1 \emptyset}$, Renato de Melo Sarges ${ }^{1 \oplus}$, Mariane Araújo Ramos ${ }^{1 \oplus}$, Maurício José \\ Cordeiro Souza $^{1 \bullet}$, Camila Rodrigues Barbosa Nemer ${ }^{2} \bullet$, Rubens Alex de Oliveira Menezes ${ }^{2 *} \bullet$
}

${ }^{1}$ Faculdade Madre Tereza, Santana, Amapá, Brasil. ${ }^{2}$ Departamento de Ciências Biológicas e da Saúde, Universidade Federal do Amapá,
Macapá, Amapá, Brasil. *Autor para correspondência. E-mail: ra-menezes@hotmail.com/rubens.alex@unifap.br

Resumo: Introdução: O Câncer de Estômago (ou Câncer Gástrico) é o crescimento de células anormais no órgão desse sistema digestivo e pode ocorrer em qualquer local de sua extensão. Grande parte desse tipo de tumor ocorre na camada mucosa (a camada de revestimento interna), surgindo na forma de irregulares pequenas lesões com ulcerações (rompimento do tecido mucoso) - características de cânceres ou tumores malignos. Objetivo: Caracterizar o perfil clínico epidemiológico do câncer gástrico em pacientes portadores da doença. Revisão: Trata-se de uma revisão integrativa desenvolvida em cinco etapas: busca criteriosa nas bases de dados LILACS e MEDLINE; seleção dos artigos, dissertações, teses e monografias de acordo com os critérios de inclusão e exclusão da temática proposta; análise dos artigos, dissertações, teses e monografias, que serão adequados em categorias de acordo com a abordagem; ano de publicação, que serão do tipo de estudo e periódico em que foi publicado; construção do artigo e defesa pública do mesmo. Resultados: Nesta revisão integrativa foram analisados 04 artigos que atenderam aos critérios de inclusão previamente estabelecidos. Considerações finais: A pesquisa evidenciou a maior incidência de câncer gástrico no sexo masculino nas idades de 40 a 60 anos, mas essa incidência vem diminuindo, segundo alguns artigos recentes, a escolha de hábitos alimentares saudáveis e a diminuição de consumo de bebidas alcoólicas e do habito de fumar, são fatores favoráveis para o declínio desta patologia.

Palavras-chave: adenocarcinoma, câncer gástrico, hábitos alimentares, neoplasias gástricas, promoção da saúde, sistema digestivo.

\begin{abstract}
Introduction: Stomach Cancer (or Gastric Cancer) is the growth of abnormal cells in the organ of this digestive system and can occur anywhere in its extension. Much of this type of tumor occurs in the mucous layer (the inner lining layer), appearing in the form of irregular small lesions with ulcerations (rupture of the mucous tissue) - characteristics of cancers or malignant tumors. Objective: To characterize the clinical epidemiological profile of gastric cancer in patients with the disease. Revision: It is an integrative review developed in five stages: careful search in the LILACS and MEDLINE databases; selection of articles, dissertations, theses and monographs according to the inclusion and exclusion criteria of the proposed theme; analysis of articles, dissertations, theses and monographs, which will be suitable in categories according to the approach; year of publication, which will be the type of study and journal in which it was published; construction of the article and public defense of it. Results: In this integrative review, 04 articles were analyzed that met the inclusion criteria previously established. Final considerations: The research showed the highest incidence of gastric cancer in males between the ages of 40 and 60 , but this incidence has been decreasing, according to some recent articles, the choice of healthy eating habits and the decrease in consumption of alcoholic beverages and smoking habits, are favorable factors for the decline of this pathology.
\end{abstract}

Keywords: adenocarcinoma, stomach cancer, feeding behavior, stomach neoplasms, health promotion, digestive system.

\section{Introdução}

O Câncer Gástrico (Câncer de Estômago) é o crescimento de células anormais do sistema digestivo e pode ocorrer em qualquer local de sua extensão. Geralmente, parte desse tipo de tumor ocorre na camada da mucosa (a camada de revestimento interna), surgindo na forma de irregulares pequenas lesões com ulcerações (rompimento do tecido mucoso) características de cânceres ou tumores malignos (Amorim, 2013). Conforme 
Brasil (2012), o câncer gástrico se apresenta, predominantemente, na forma de três tipos histológicos: adenocarcinoma (responsável por 95\% dos tumores), linfoma, diagnosticado em cerca de $3 \%$ dos casos, e leiomiossarcoma, iniciado em tecidos que dão origem aos músculos e aos ossos.

A incidência em sua maioria em homens, por volta dos 70 anos. Adicionalmente, cerca de $70 \%$ dos pacientes diagnosticados com câncer de estômago têm mais de 50 anos. No Brasil, esses tumores aparecem em terceiro lugar na incidência entre homens e em quinto, entre as mulheres. No resto do mundo, dados estatísticos revelam declínio da incidência, especificamente nos Estados Unidos, Inglaterra e outros países mais desenvolvidos. A alta mortalidade é registrada na América Latina, principalmente na Costa Rica, Chile e Colômbia. Porém, o maior número de casos ocorre no Japão, onde são encontrados 780 doentes por 100.000 habitantes (Brasil, 2015).

Os cânceres gástricos são, em sua maioria, adenocarcinomas, podem ocorrer em qualquer parte do estômago. Tipicamente, o câncer gástrico ocorre em indivíduos com mais de 40 anos de idade (ocasionalmente, em indivíduos mais jovens). Os norte-americanos de origem asiática, os indígenas norteamericanos, os hispano-americanos e os afro-americanos têm duas vezes mais probabilidade de desenvolver câncer gástrico que os norte-americanos caucasianos. A incidência do câncer gástrico é muito maior no Japão (Nakajima, 2002; Amorim, 2013).

A dieta parece constituir um fator significativo (dieta rica em alimentos defumados e pobres em frutas e vegetais). Outros fatores relacionados com a incidência do câncer gástrico incluem inflamação crônica do estômago, infecção por Helicobacter pylori, anemia perniciosa, tabagismo, acloridria, úlceras gástricas e genética. Em geral, o prognóstico é reservado, visto que a maioria dos clientes apresenta metástases (para o fígado, o pâncreas e o esôfago ou duodeno) por ocasião do diagnóstico (Souza \& Voeux, 2015).

Esse tipo de câncer é um problema de saúde pública em países desenvolvidos e em desenvolvimento, sendo responsável por mais de seis milhões de óbitos a cada ano, representando cerca de $12 \%$ de todas as causas de morte no mundo (Brasil, 2012). A estimativa 2014/2015 é de 576 mil novos casos de cânceres, dos quais 20 mil estão relacionados ao câncer gástrico, sendo $65 \%$ desses casos diagnosticados em homens acima de 50 anos. Nas regiões Norte e Nordeste do Brasil encontra-se o terceiro maior índice entre a população (6 por 100 mil casos) (Brasil, 2015).

A incidência se dá em sua maioria em homens, por volta dos 70 anos. Cerca de $65 \%$ dos pacientes diagnosticados com câncer de estômago têm mais de 50 anos. No Brasil, esses tumores aparecem em terceiro lugar na incidência entre homens e em quinto, entre as mulheres. No resto do mundo, dados estatísticos revelam declínio da incidência, especificamente nos Estados Unidos, Inglaterra e outros países mais desenvolvidos (Brasil, 2012, 2015).

Para a Organização Mundial de Saúde, o câncer de estomago nos Estados Unidos e Inglaterra revelaramse em declínio, enquanto em países da América Latina como: Chile, Costa Rica e Colômbia é alto o índice de mortalidade. Porém o maior número de casos encontra-se no Japão com média de 780 doentes por 100.000 habitantes. O interesse nos aspectos epidemiológicos do Câncer gástrico tem aumentado. A melhor compreensão destes dados talvez possibilite a relação com possíveis fatores causais, contribuindo para o desenvolvimento de estratégias de prevenção (Brasil, 2012).

Ademais, no Japão, país com alta incidência da doença, o conhecimento epidemiológico propiciou o estabelecimento de medidas direcionadas ao rastreamento desta neoplasia, como a realização de exames endoscópicos periódicos (Kato \& Asaka, 2012). O diagnóstico precoce, por sua vez, contribui para um tratamento mais eficaz, menos agravos à saúde e um custo menor. No Brasil, o câncer gástrico é importante causa de morbimortalidade com escassos estudos sobre o tema. Norteado por tais discussões, o objetivo desta pesquisa é discutir o câncer gástrico, relacionando com as evidências cientificas publicadas em bases de dados sobre a temática.

\section{Revisão}

Trata-se de uma revisão integrativa da literatura (RIL), a qual permite a síntese de múltiplos estudos publicados e possibilita conclusões gerais a respeito da área de estudo. A presente RIL foi desenvolvida em cinco etapas: busca criteriosa nas bases de dados LILACS e MEDLINE; seleção dos artigos, dissertações, teses e monografias de acordo com os critérios de inclusão e exclusão da temática proposta; análise dos artigos, dissertações, teses e monografias, que serão adequados em categorias de acordo com a abordagem; ano de publicação, que serão do tipo de estudo e periódico em que foi publicado; construção do artigo e defesa pública do mesmo. 
Foram utilizados como critérios de inclusão: artigos oriundos das bases LILACS e MEDLINE; publicados na integra entre os anos de 2010 e 2017, em português, e que abordaram o tema em destaque, com indexação nas bases de dados Literatura Latino Americano e do Caribe em ciências da saúde (LILACS), na Medical Literature Analysis and Retrieval System Online (MEDLINE). Como critério de Exclusão: publicações diferentes de artigos, que não objetem a todos os critérios dos objetivos específicos, às quais não seja plausível o acesso gratuito ao texto finalizado, publicações repetidas, artigos elaborados fora da data proposta.

A ferramenta utilizada de busca dos artigos foi a Biblioteca Virtual de Saúde (BVS), que engloba várias bases de dados, incluindo LILACS e MEDLINE. Os descritores em ciências da saúde (DeCs) usados foram "câncer gástrico". A consulta na base de dados foi realizada em agosto e setembro de 2018. Para a coleta de dados, foi utilizado um instrumento que agrega os seguintes aspectos: nome da pesquisa, autor da pesquisa, ano, objetivo da pesquisa, método e resultados. Utilizando-se o descritor mencionado, procedeu-se à busca na BVS, emergindo 83.580 publicações.

A partir disso, iniciou-se a utilização dos critérios de inclusão como filtros dos artigos. Primeiro, foram utilizados como filtro publicações na integra, emergindo 26.307 dos 83.580 iniciais. Após, foram utilizados como filtro as Bases de Dados, que emergiu 26.289 publicações dos 83.580 iniciais. A seguir foi utilizado o filtro Assuntos Principais: neoplasias gástricas; adenocarcinoma; infecções por Helicobacter; Helicobacter Pylori e Mucosa Gástrica, que se deu em 23.281 publicações dos 83.580 iniciais. Seguindo foi feito o filtro Limite, que emergiu em 22.447 publicações dos 83.580 iniciais.

Após, foram utilizados como filtro o Ano de Publicação de 2010 a 2017, que se deu em 16.827 publicações dos 83.580 iniciais. (Após, foram utilizados como filtro publicações.) Seguindo, como filtro Tipo de Documento, emergindo 65 publicações dos 83.580 iniciais. Após, foram utilizados como filtro, que se deu em artigos publicados em português e Inglês, surgindo 65 publicações dos 83.580 iniciais. Após essa seleção, utilizando os critérios de inclusão como filtros na BVS, foi realizada a leitura dos 65 artigos, sendo selecionados 20 artigos, utilizando os critérios de exclusão. Após, foi realizada a leitura criteriosa do resumo dos 20 artigos, sendo selecionados 04 .

Logo em seguida, realizou-se a leitura na íntegra dos artigos, sendo incluídos neste estudo 04 artigos. Após essa seleção, a exclusão de artigos se caracterizou em estudos de artigos repetidos, artigos elaborados fora da data proposta e artigos que não se adequaram ao objetivo deste. Assim, foram incluídos nesta RIL quatro (04) artigos que se adequaram ao objetivo deste. Os artigos excluídos após leitura eram estudos não disponíveis, artigos pagos, repetidos, fora da data proposta dos estudos de revisão, carta ao editor e estudos que não se enquadravam no objetivo deste. Assim, foram incluídos nesta RIL 04 artigos que se adequavam ao objetivo deste.

\section{Discussão}

Nesta RIL foram analisados 04 artigos que atenderam aos critérios de inclusão previamente estabelecidos. A seguir, apresentar-se um panorama geral dos artigos analisados nos quadros 1 e 2 . Dentre os artigos analisados, (1) um estava indexado na base de dados MEDLINE e três estavam indexados na base de dados da LILACS. Destes artigos, o A1 foi publicado no ano de 2014 na Biblioteca Digital de Teses e Dissertações da USP: o A2 no ano de 2015 na Arq. Gastroenterol: o A3 foi publicado no ano de 2011 na Revista Brasileira de Cancerologia e o A4 foi publicado na RevInter Revista de Intertox de Toxicologia no ano de 2014.

Quadro 1. Síntese dos artigos incluídos na Revisão Integrativa da Literatura.

\begin{tabular}{|c|c|c|c|c|}
\hline Número & $\begin{array}{l}\text { Autor, ano, } \\
\text { revista, país. }\end{array}$ & Título & Objetivo & Método \\
\hline A1 & $\begin{array}{c}\text { Tahara, } 2014 . \\
\text { Rev. Biblioteca } \\
\text { Digital de Teses e }\end{array}$ & $\begin{array}{c}\text { Tendências das } \\
\text { incidências e da } \\
\text { mortalidade de São } \\
\text { Paulo } 2014\end{array}$ & $\begin{array}{c}\text { Analisar as tendências dos } \\
\text { coeficientes de incidência de } \\
\text { mortalidade do câncer de } \\
\text { estômago, segundo sexo, faixa }\end{array}$ & $\begin{array}{c}\text { Foram analisados } 24.512 \text { casos } \\
\text { incidentes e } 31.215 \text { óbitos. Houve } \\
\text { redução da incidência (APC - 8,3\% em } \\
\text { homens e } 6,5 \% \text { em mulheres e da }\end{array}$ \\
\hline
\end{tabular}




\begin{tabular}{|c|c|c|c|c|}
\hline & $\begin{array}{l}\text { Dissertações da } \\
\text { USP. Brasil. }\end{array}$ & & $\begin{array}{l}\text { etária e tipo histológica pela } \\
\text { classificação de Louren. }\end{array}$ & $\begin{array}{l}\text { mortalidade (APC - 2,3\% em homens e } \\
\text { 2,5\% em mulheres). Houve tendência de } \\
\text { queda em todas as faixas etárias, com } \\
\text { exceção da faixa etária mais jovem ( } 2029 \\
\text { anos), que apresentou estabilidade da } \\
\text { incidência e da mortalidade. A } \\
\text { estabilidade na faixa etária mais jovem } \\
\text { também foi identificada nos tipos } \\
\text { intestinais e difuso. O tipo difuso } \\
\text { apresentou estabilidade também nas } \\
\text { faixas etárias: } 30-39,40-49 \text { e } \geqslant 80 \text { anos } \\
\text { do sexo feminino. }\end{array}$ \\
\hline $\mathrm{A} 2$ & $\begin{array}{l}\text { Vinagre et al., } \\
\text { 2015. Rev. Arq } \\
\text { Gastroenterol. }\end{array}$ & $\begin{array}{c}\text { Helicobacter Pylori } \\
\text { Infection In Patients } \\
\text { With Different } \\
\text { Gastrointestinal } \\
\text { Diseases From } \\
\text { Northern Brazil }\end{array}$ & $\begin{array}{l}\text { O objetivo desse estudo foi } \\
\text { investigar a presença da } \\
\text { infecção por H. pylori, e a } \\
\text { frequência dos diferentes } \\
\text { genótipos dessa bactéria em } \\
\text { pacientes com doenças } \\
\text { gastrointestinais da nossa } \\
\text { região, procurando } \\
\text { estabelecer sua associação } \\
\text { com os achados } \\
\text { histopatológicos. }\end{array}$ & $\begin{array}{c}\text { Em estudos prospectivos, foram } \\
\text { coletadas amostras de } 554 \text { pacientes com } \\
\text { diferentes doenças gastrointestinais } \\
\text { (gastrite, úlcera duodenal, úlcera gástrica } \\
\text { e câncer gástrico), atendidos em hospital } \\
\text { de referência para todo o Estado do Pará, } \\
\text { localizado na região metropolitana de } \\
\text { Belém. Foram analisados dados obtidos } \\
\text { através de questionário epidemiológico, } \\
\text { relacionados ao sexo e faixa etária desses } \\
\text { pacientes. A presença do H. pylori e do } \\
\text { genótipo bacteriano foi detectada } \\
\text { utilizando a PCR. As biopsias gástricas } \\
\text { foram avaliadas histologicamente. }\end{array}$ \\
\hline A3 & $\begin{array}{l}\text { Campelo \& Lima, } \\
\text { 2012. Revista } \\
\text { Brasileira de } \\
\text { Cancerologia. } \\
\text { Brasil. }\end{array}$ & $\begin{array}{c}\text { Perfil clinico } \\
\text { epidemiológico do } \\
\text { câncer gástrico } \\
\text { precoce em um } \\
\text { hospital de } \\
\text { referência em } \\
\text { Teresina, Piauí. }\end{array}$ & $\begin{array}{l}\text { Caracterizar o perfil clinico } \\
\text { epidemiológico do câncer } \\
\text { gástrico precoce tratados no } \\
\text { hospital de referência em } \\
\text { oncologia de Teresina no } \\
\text { período de } 2004 \text { a } 2009 .\end{array}$ & $\begin{array}{l}\text { Realizou-se um estudo descritivo, } \\
\text { retrospectivo e quantitativo através de } \\
\text { revisão prontuário com os casos } \\
\text { confirmados de câncer gástrico precoce } \\
\text { atendidos no hospital de } 2004 \text { e } 2009\end{array}$ \\
\hline $\mathrm{A} 4$ & $\begin{array}{l}\text { Oliveira et al., } \\
\text { 2014. Brasil. }\end{array}$ & $\begin{array}{c}\text { Relação entre } \\
\text { consumo alimentar } \\
\text { da população } \\
\text { nordestina e o alto } \\
\text { índice de câncer } \\
\text { gástrico nesta } \\
\text { região. }\end{array}$ & $\begin{array}{c}\text { Teve como objetivo cruzar } \\
\text { dados do perfil alimentar da } \\
\text { população do nordeste } \\
\text { brasileiro com estudos que } \\
\text { investigaram a relação entre } \\
\text { as neoplasias gástricas e os } \\
\text { principais alimentos } \\
\text { consumidos, para explicar a } \\
\text { alta incidência desta neoplasia } \\
\text { na região. }\end{array}$ & $\begin{array}{l}\text { Foi realizado uma revisão de literatura, } \\
\text { por meio de buscas bibliográficas nos } \\
\text { bancos de dados informatizados } \\
\text { Medline/Pubmed, Scielo e Lilacs, no } \\
\text { período de maio a julho de 2013, } \\
\text { considerando artigos que investigaram a } \\
\text { relação entre neoplasias gástricas e a } \\
\text { alimentação. }\end{array}$ \\
\hline
\end{tabular}

Fonte: Primária. 
Quadro 2. Síntese dos artigos incluídos na Revisão Integrativa da Literatura.

\begin{tabular}{|c|c|c|c|}
\hline Número & Descritores & Resultados & Considerações Finais \\
\hline A1 & Câncer de Estômago & $\begin{array}{l}\text { Foram analisados } 24.512 \text { casos incidentes e } \\
31.215 \text { óbitos. Houve redução da incidência } \\
\text { (APC - 8,3\% em homens e 6,5\% em mulheres e } \\
\text { da mortalidade (APC - 2,3\% em homens e 2,5\% } \\
\text { em mulheres). Houve tendência de queda em } \\
\text { todas as faixas etárias, com exceção da faixa } \\
\text { etária mais jovem (2029 anos), que apresentou } \\
\text { estabilidade da incidência e da mortalidade. A } \\
\text { estabilidade na faixa etária mais jovem também } \\
\text { foi identificada nos tipos intestinais e difuso. O } \\
\text { tipo difuso apresentou estabilidade também nas } \\
\text { faixas etárias: } 30-39,40-49 \text { e } \geqslant 80 \text { anos do sexo } \\
\text { feminino. }\end{array}$ & $\begin{array}{l}\text { São Paulo acompanhou a tendência } \\
\text { mundial de decréscimo na incidência e na } \\
\text { mortalidade, entretanto, a mesma } \\
\text { tendência não foi observada entre adultos } \\
\text { jovens, principalmente a faixa etária de } 20 \\
\text { a } 29 \text { anos. Atenção especial deve ser dada } \\
\text { ao tipo difuso, que não apresentou queda } \\
\text { na tendência de incidência do câncer de } \\
\text { estomago para as mulheres de } 20 \text { a } 49 \text { anos }\end{array}$ \\
\hline A2 & $\begin{array}{c}\text { "Helicobacter pylori” } \\
\text { "Helicobacter } \\
\text { infections" } \\
\text { "Gastrointestinal } \\
\text { diseases" "Genotype” }\end{array}$ & $\begin{array}{l}\text { Observou-se uma prevalência de 91\% da } \\
\text { infecção pelo H. pylori, sendo mais frequente } \\
\text { nos portadores de úlcera gástrica e câncer } \\
\text { gástrico, nos quais houve predomínio do sexo } \\
\text { masculino e a idade foi maior que a dos outros } \\
\text { dois grupos estudados. O genótipo bacteriano } \\
\text { predominante foi o s1m1cagA positivo, sendo } \\
\text { mais frequentes entre os pacientes com úlcera } \\
\text { gástrica, úlcera duodenal e câncer gástrico. } \\
\text { Houve associação significante das cepas com o } \\
\text { genótipo s1m1cagA positivo com maior grau de } \\
\text { inflamação, atividade neutrofílica e } \\
\text { desenvolvimento de metaplasia intestinal. }\end{array}$ & $\begin{array}{l}\text { Nosso estudo demonstra a alta incidência } \\
\text { da infecção pelo H. pylori nos pacientes } \\
\text { analisados em nosso meio, especialmente } \\
\text { em portadores de úlcera e câncer gástricos. } \\
\text { As cepas virulentas s1m1cagA+ foram } \\
\text { predominantes e estavam associadas a } \\
\text { lesões mais graves. }\end{array}$ \\
\hline A3 & $\begin{array}{l}\text { “Câncer” “Gástrico” } \\
\text { “Estômago” “Precoce” }\end{array}$ & $\begin{array}{l}\text { Foram estudados } 22 \text { pacientes correspondendo a } \\
3,8 \% \text { de todos os casos de câncer gástrico, sendo } \\
13 \text { (59\%) do sexo masculino a média de idade foi } \\
59,7 \text { anos. O sintoma mais comum foi a } \\
\quad \text { epigastralgia ( } \mathrm{n}=10,38,5 \%) \text {. O local } \\
\text { predominante foi o antro gástrico ( } \mathrm{n}=12,54 \%) \text { e } \\
\text { a camada mais acometida foi a submucosa (n= } \\
14,68,2 \%) \text {. Os tipos macroscópicos mais } \\
\text { registrados foram o Ilc e III com } 7 \text { ( } 31 \% \text { ) casos } \\
\text { cada. O tratamento realizado foi o cirúrgico com } \\
\text { a gastrectomia total a técnica mais utilizada (n= } \\
13,59 \%)\end{array}$ & $\begin{array}{c}\text { O câncer gástrico precoce é pouco } \\
\text { diagnosticado, sendo uma realidade } \\
\text { observada em estudos ocidentais e segue o } \\
\text { perfil semelhante ao descritos na } \\
\text { literatura. }\end{array}$ \\
\hline A4 & $\begin{array}{c}\text { Neoplasias Gástricas e } \\
\text { Alimentação. }\end{array}$ & $\begin{array}{l}\text { Foram encontrados } 43 \text { artigos, dos quais } 21 \\
\text { atenderam aos critérios de inclusão do estudo, e } \\
\text { estes foram divididos em dois grupos. O } \\
\text { primeiro com as características alimentares do } \\
\text { Nordeste, e o segundo, a influência dos } \\
\text { alimentos tradicionais nas neoplasias gástricas. }\end{array}$ & $\begin{array}{l}\text { Portanto, pode-se notar que a alimentação } \\
\text { da população nordestina parece possuir } \\
\text { uma estreita relação com o } \\
\text { desenvolvimento e a alta incidência do } \\
\text { câncer gástrico, sendo um fator de risco a }\end{array}$ \\
\hline
\end{tabular}




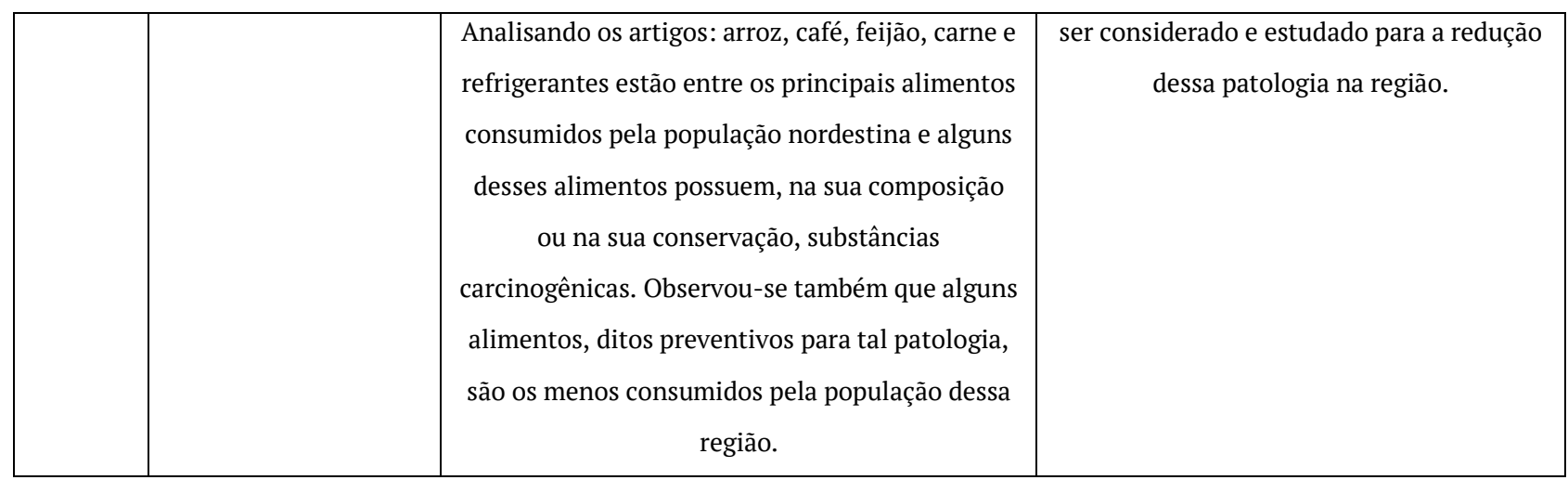

Fonte: Primária.

A partir da análise de 65 estudos encontrados no Banco Virtual de Saúde (BVS) conforme os descritores, foram selecionados para a pesquisa 04 artigos (quadro 1 e 2), nos idiomas português e inglês, com predominância do Brasil como país de origem das publicações. Todos os artigos foram encontrados na base de dados MEDLINE e LILACS. Os artigos foram publicados nos seguintes periódicos: 25\% (A1) dos artigos publicados na revista Rev. Biblioteca Digital de Teses e Dissertações da USP, 2014. Em relação ao tipo de pesquisa, 25\% do (A1) foi pesquisa dissertativa, o local de pesquisa Brasil; 25\% (A2) dos artigos publicados nas revistas Arq. Gastroenterol, em relação ao tipo de pesquisa, 25\% (A2) foi um estudo prospectivo, local da pesquisa no norte do Brasil; 25\% (A3) dos artigos Revista Brasileira de Cancerologia 2012, em relação ao tipo de pesquisa $25 \%$ (A3) foi um estudo descritivo, retrospectivo quantitativo, local de pesquisa Teresina, Piauí, Brasil; 25\% (A4) dos artigos publicados na RevInter Revista Intertox de Toxologia em 2014, em relação ao tipo de pesquisa, 25\% (A4) foi uma pesquisa de revisão de literatura, local de pesquisa, Brasil.

O câncer de estômago já foi, mundialmente, a neoplasia com maior ocorrência na população. Ao longo das décadas, a incidência deste câncer apresenta tendência de decréscimo significativo, sendo que, atualmente, é o quinto tumor maligno mais frequente no mundo. Ao analisar os artigos A1, A2, A3, A4, percebeu-se que há vários fatores que predominam na incidência do câncer gástrico e fatores alimentares das regiões onde se realizou-se as pesquisas. Feitas as análises dos artigos optamos em dividir as categorias em: Fatores Ambientais e Fatores Nutricionais.

\section{Fatores Nutricionais}

Nos artigos A1, A3 e A4, abordaram que os fatores alimentares que são uma das principais causas que levam ao câncer gástrico. No estudo A2 foi abordado sobre a Infecção por H. Pylori, e a frequência dos diferentes genótipos que ocorreu em pacientes gastrointestinais. Os fatores de risco associado ao câncer gástrico prevalente nos artigos estudados geralmente são: alimentares, tabagismo, álcool e fator hereditário. Os estudos A1, A3 e A4 enfatizam o uso excessivo de sal na alimentação, resultando inicialmente, em gastrite atrófico, aumentando o risco de desenvolver o câncer de estômago (Tsugane \& Sasazuki, 2007).

A relação entre câncer gástrico e nutrição é apontada em vários estudos, sendo a dieta um fator exógeno bastante relevante. Entre os fatores dietéticos associados ao câncer gástrico vale ressaltar que dietas com altas concentrações de cloreto de sódio, nitrito e nitrato presentes em alimentos defumados e frituras, são o ponto inicial para provocar transformações na mucosa gástrica, podendo dar início a esta neoplasia (Melo et al., 2012).

Acredita-se que cerca de 35\% dos diversos tipos de câncer ocorrem em razão de dietas inadequadas. É possível identificar, por meio de estudos epidemiológicos, associações relevantes entre alguns padrões alimentares observados em diferentes regiões do globo e a prevalência de tal patologia (Garófolo et al., 2004). Segundo os estudos A1 e A3 o sal é considerado um fator que lesa a mucosa gástrica, facilitando a ação de agentes genotóxicos (Gerra et al., 2005).

Diversos estudos experimentais feitos em animais que receberam dietas ricas em sal resultaram em atrofia gástrica, que tem forte associação com metaplasia, além de facilitar a carcinogênese no estômago na presença de outros carcinógenos. O sal, hoje imputado como um fator que lesa a mucosa gástrica facilitando a ação de agentes genotóxicos. Evidências experimentais foram obtidas com ratos que receberam dietas ricas em sal, comprovando que este leva à atrofia gástrica, além de estar fortemente associado a metaplasia, facilitar a carcinogênese no estômago na presença de outros carcinógenos (Shils et al., 2003, Souza, Ribeiro, \& Ferreira, 2017). 
Ademais, o elevado consumo de alimentos enlatados e embutidos (aditivos utilizados na conservação), também apresentam riscos, pois quando metabolizadas no organismo, se transformam em nitrosaminas, substâncias altamente cancerígenas. Outra substância que apresentam risco a formação de câncer seria o alcatrão, presente na fumaça do tabaco e em carnes de churrasco devido à queima do carvão (Bonequi et al., 2013, Brasil, 2016, Raei et al., 2016, Silva \& Felicio, 2016).

De acordo com o estudo A1 e A4, o uso dos compostos de nitrato, nitrito e nitroso, podem gerar prédisposição para o câncer gástrico. Entre os alimentos apontados como os que elevam o risco de desenvolver o câncer de estômago estão, principalmente: defumados, carnes curadas, peixes secos e outros alimentos conservados em sal. Está bem documentado na literatura que os compostos N-nitrosos e o nitrato induzem à formação tumoral por meio da sua transformação em nitrito, um óxido desestabilizado, que pode acarretar danos ao material genético, causando assim uma lesão celular (Souza, Ribeiro, \& Ferreira, 2017).

$\mathrm{O}$ nitrito, que pode ser formado endogenamente, também provém das carnes curadas (conservadas com nitrito de sódio), embutidos e alguns vegetais (espinafre, batata, beterraba, alface, tomate, cenoura, nabo, couve-flor, repolho, rabanete, etc.) que contêm nitrato, o qual é transformado em nitrito pela ação da saliva. Os mecanismos postulados para o aumento do risco do câncer de estômago com o consumo de compostos nitrosos estão associados ao aumento de radicais livres, que promovem lesão celular com redução na produção de muco, um fator de proteção à mucosa gástrica (Magalhães et al., 2008).

\section{Fatores Ambientais}

De acordo com o artigo A1, o álcool é um irritante gástrico que tem importante fator de risco para o câncer de estômago, aqueles que bebiam vodca, pelo menos uma vez por semana, tiveram risco três vezes maior de ter câncer gástrico quando comparado com aqueles que não bebiam. O aumento dos níveis de acetaldeído induzidas pelo consumo excessivo de álcool pode levar a danos no DNA e, posteriormente, aumentar o risco de câncer gástrico. Úlceras gástricas induzidas por etanol são ocasionadas devido a vários mecanismos, incluindo a depleção de muco gástrico e da permeabilidade da mucosa (Jeongseon et al., 2014; Huang et al., 2013; Dias et al., 2016).

Sobre o estudo A1, o tabagismo é fator de risco para o câncer de estômago do grupo 1, com evidência suficiente de carcinogenicidade em seres humanos. O tabagismo foi outro fator de risco para o câncer gástrico investigado. Foi observado que 16 (66,7\%) clientes fumaram ou ainda estavam fumando. Esses últimos indicaram ter o hábito há pelo menos por um período em média de 35 a 50 anos; quanto aos ex-fumantes, referiram ter fumado por um período de 20 a 40 anos. Cerca de $30 \%$ dos óbitos por câncer de estômago ocorrem em fumantes. Fumar tem sido consistentemente relatado como o mais importante fator de risco comportamental para câncer gástrico, retardando a cicatrização de úlceras em seres humanos (Zilberstein et al., 2014; Wang et al., 2014).

O estudo A2 foi abordado sobre a Infecção por H. Pylori, e a frequência dos diferentes genótipos que ocorreu em pacientes gastrointestinais. De acordo com o estudo A2, a Infecção por H. Pylori, é a frequência dos diferentes genótipos que ocorreu em pacientes gastrointestinais. Parentes em primeiro grau de pacientes com câncer de estomago tem o risco aumento em cerca de duas a três vezes. Podem contribuir para o aumento deste risco: a hereditariedade pela infecção por H. pylori, pelo grupo de sangue tipo A e/ou por presença de pólipos gástricos (Dantas et al., 2009).

O Helicobacter pylori é uma bactéria gram-negativa em espiral que infecta mais de metade da população mundial. Além de seu papel indiscutível na gastrite crônica e úlcera péptica, a associação entre H. pylori e câncer gástrico também é bem aceito e estudos epidemiológicos estimam que o risco de câncer gástrico em indivíduos infectados pela bactéria é aumentado em 20 vezes. Atualmente, a infecção por esse patógeno é considerada o fator de risco mais importante para o aparecimento do câncer gástrico (Shiota et al., 2014; Merchant \& Kim, 2014; Pandey et al., 2014).

O estudo A2, mostrou que o grupo sanguíneo A é mais fortemente associado ao tipo histopatológico difuso de câncer gástrico. Adicionalmente, o mesmo estudo provou significativa relação entre o grupo sanguíneo $\mathrm{O}$ associado com alto risco para o desenvolvimento de úlcera péptica e o desenvolvimento de câncer gástrico antes dos 50 anos. O grupo sanguíneo A está associado com alto risco para câncer de estômago quando comparado com os outros tipos sanguíneos. Um estudo na Coréia para investigar se há diferenças específicas do sexo no genótipo associado ao grupo $\mathrm{ABO}$ quanto ao risco de câncer gástrico, sendo os genótipos $\mathrm{AA}$ e $\mathrm{AO}$ associado ao sexo feminino e apenas para o tipo difuso sugerindo que a associação entre o grupo sanguíneo ABO e risco para câncer gástrico pode variar de acordo com o sexo e tipo histológico (Edgren et al., 2010; Wang et al., 2012). 


\section{Considerações finais}

O estudo integra vários artigos relacionados sobre o tema abordado, auxiliando no aprendizado de futuros profissionais, trazendo informações recentes que aponta os fatores ambientais e nutricionais como responsáveis para o surgimento do câncer gástrico. O consumo de bebidas alcoólicas, tabagismo e fator RH, são fatores ambientais que foram abordados nos artigos estudados. Já nos fatores nutricionais, o tipo de hábitos alimentares e a conservação dos alimentos foram temas bastantes discutidos nos artigos estudados.

Analisando os fatores de risco, a maior incidência de câncer gástrico se dar no sexo masculino com idade acima de 50 anos, sendo os hábitos alimentares saudáveis e a diminuição de consumo de bebidas alcoólicas e do habito de fumar, fatores favoráveis para o declínio desta patologia. Todavia, a despeito da relevância desse tema, verificou-se a existência limitada de pesquisas publicadas, o que aponta para a necessidade de mais estudos sobre o assunto.

\section{Referências}

Amorim, C. A. F. L. 2013. Distribuição e avaliação geográfica do câncer gástrico no brasil entre 2005-2010. Dissertação de Mestrado (Clínica Médica). Rio de Janeiro, RJ: UFRJ.

Bonequi, P., Meneses-González, F., Correa, P., Rabkin, C. S., \& Camargo, M. C. 2013. Risk factors for gastric cancer in Latin America: a meta-analysis. Cancer Causes Control, 24(2), 217-231.

Brasil. 2012. ABC do câncer: abordagens básicas para o controle do câncer/INCA. Rio de Janeiro, RJ: Ministério da Saúde. Instituto Nacional de Câncer

Brasil. 2015. Estimativa 2015: Incidência de câncer no Brasil/Instituto Nacional de Câncer. Rio de Janeiro, RJ: Ministério da Saúde. Instituto Nacional de Câncer

Souza, S. R., \& Voeux, P. L. (2015). Brunner \& Suddarth: Manual de enfermagem médico-cirúrgica (13a ed.). Rio de Janeiro: Guanabara Koogan.

Campelo, J. C. L., \& Lima, L. C. 2012. Perfil clinicoepidemiológico do Câncer Gástrico Precoce em um Hospital de Referência em Teresina, Piauí. Revista Brasileira de Cancerologia, 58(1), 15-20.

Dantas, É. L. R, Sá, F. H. L., Carvalho, S. M. F., Arruda, A. P., Ribeiro, E. M., \& Ribeiro, E. M. 2009. Genética do câncer hereditário. Revista Brasileira de Cancerologia, 55(3), 263-269.

Dias, A. A., Helmer, J. L., Azevedo, S. K. B. C., Caldato, C., Oliveira, C. M., Moreira, R. C., ... Oliveira, E. 2016. Fatores de Risco genético e ambientais para o câncer gástrico. Revista cientifica multidisciplinar Núcleo do conhecimento, 11(10), 63-72.

Edgren, G., Hjalgrim, H., Rostgaard, K., Norda, R., Wikman, A., Melbye, M., \& Nyrén, O. 2010. Risk of gastric cancer and peptic ulcers in relation to ABO blood type: a cohort study. American journal of epidemiology, 172(11), 1280-1285

Garófolo, A., Avesani, C. M., Camargo, K. G., Barros, M. E., Silva, S. R. J., Taddei, J. A. A. C., \& Sigulem, D. M. 2004. Dieta e câncer: um enfoque epidemiológico. Revista de Nutrição, 17(4), 491-505.

Huang, C. C., Chen, Y. M., Wang, D. C., Chiu, C. C., Lin, W. T., Huang, C. Y., \& Hsu, M. C. 2013. Cytoprotective effect of American ginseng in a rat ethanol gastric ulcer model. Molecules, 19(1), 316-326.

Jeongseon, K., Cho, Y. A., Choi, W. J., \& Jeong, S. H. 2014. Gene-diet interactions in gastric cancer risk: a systematic review. World Journal of Gastroenterol, 20(28),9600-9610.

Kato, M, \& Asaka, M. 2012. Recent development of gastric cancer prevention. Japanese Journal of Clinical Oncology, 42(11), 987-9420.

Magalhães, L. P., Oshima, C. T. F., Souza, L. G., Lima, J. M. de, Carvalho, L., \& Forones, N. M. 2008. Variação de peso, grau de escolaridade, saneamento básico, etilismo, tabagismo e hábito alimentar pregresso em pacientes com cancêr de estômago. Arquivos de Gastroenterologia, 45(2), 111-116.

Melo, M. M., Nunes, L. C., \& Leite, I. C. G. 2012. Relationship between dietary factors and anthopometric and gastrointestinal tract neoplasms: Investigations done in Brazil. Revista Brasileira de Cancerologia, 58(1), 85-95.

Merchant, S. J., Li, L., \& Kim, J. (2014). Racial and ethnic disparities in gastric cancer outcomes: more important than surgical technique?. World Journal of Gastroenterology, 20(33), 11546. 
Nakajima, T. 2002. Gastric cancer treatment guidelines in Japan. Gastric Cancer, 5(1), 1-5.

Oliveira, V. A. Oliveira, T. W. N., Alencar, M. V. O. B., Peron, A. P., \& Sousa, J. M. C. 2014. Relação entre consumo alimentar da população nordestina e o alto índice de câncer gástrico nesta região. Revinter Revista Intertox de Toxicologia, Risco Ambiental e Sociedade, 7(3), 06-24.

Pandey, A., Tripathi, S. C., Mahata, S., Vishonoi, K., Shukla, S., Misra, S. P., ... Bharti, A.C. 2014. Carcinogenic Helicobacter pylori in gastric pre-cancer and cancer lesions: association with tobacco-chewing. World Journal of Gastroenterology, 20(22), 6860-6868.

Raei, N., Behrouz, B., Zahri, S., \& Latifi-Navid, S. 2016. Helicobacter pylori Infection and Dietary Factors Act Synergistically to Promote Gastric Cancer. Asian Pacific Journal of Cancer Prevention, 17(3), 917-921.

Shils, M. E., Olson, J. A., Shike, M., \& Ross, A. C. 2003. Tratado de nutrição moderna na saúde e na doença (9a ed.). São Paulo, SP: Manole.

Shiota, S., Suzuki, R., Matsuo, Y., Miftahussurur, M., Tran, T. T. H., Binh, T. T., \& Yoshio Yamaoka, Y. 2014. Helicobacter pylori from gastric cancer and duodenal ulcer show same phylogeographic origin in the Andean region in Colombia. PLoS One, 9(8), e105392.

Silva, V. C. S, \& Felício, D. C. 2016. Fatores de Risco para o câncer gástrico em grupos de classe socioeconômico baixa: Revisão Literária. Revista De Iniciação Cientificada Universidade Vale do Rio Verde: Três corações, 6(1), 3-10.

Souza, L. T., Ribeiro, F. S., \& Ferreira, D. C. 2017. Implicações nutricionais no câncer gástrico: uma revisão. Journal of Applied Pharmaceut ical Sciences, 4(3), 2-13.

Tahara, E. I. 2014. Tendências da Incidência e da Mortalidade do Câncer de Estômago no Município de São Paulo. 2014. Dissertação de Mestrado (Faculdade de Saúde Pública). São Paulo, SP: Universidade de São Paulo.

Tsugane, S., \& Sasazuki, S. 2007. Diet and the risk of gastric cancer: review of epidemiologica l evidence. Gastric Cancer, 10,75-83.

Vinagre, I. D. F., Queiroz, A. L. de, Silva Júnior, M. R., Vinagre, R. M. D. F., \& Martins, L. C. 2015. Helicobacter pylori infection in patients with different gastrointestinal diseases from northern brazil. Arquivos de Gastroenterologia, 52(4), 266-271.

Wang, Z., Liu, L., Ji, J., Zhang, J., Yan, M., Liu, B., ... Yu, Y. 2012. ABO blood group system and gastric cancer: a case-control study and meta-analysis. International Journal of Molecular Sciences, 13, 13308-13321.

Zilberstein, B., Malheiros, C., Lourenço, L. G., Kassab, P., Jacob, C. E., Weston, A. C, ... Gama-Rodrigues, J. 2013. Consenso brasileiro sobre câncer gástrico: diretrizes para o câncer gástrico no Brasil. ABCD. Arquivos Brasileiros de Cirurgia Digestiva, 26(1), 2-6.

\section{Minicurrículo}

Flávio Souza Gonçalves. Bacharelado em Enfermagem pela Faculdade Madre Tereza - FAMAT. Santana, Amapá, Brasil.

Renato de Melo Sarges. Bacharelado em Enfermagem pela Faculdade Madre Tereza - FAMAT. Santana, Amapá, Brasil.

Mariane Araújo Ramos. Graduação em Enfermagem e especialização em obstetrícia pela Universidade Federal do Pará (2005), especialista em clínica cirúrgica pelo programa de residência do governo do Amapá e especialista em docência do ensino superior pelo IESAP-AP. Docente de Enfermagem pela Faculdade Madre Tereza - FAMAT. Santana, Amapá, Brasil.

Maurício José Cordeiro Souza. Graduado em Biomedicina pelo Centro Universitário Barão de Mauá (Ribeirão Preto - SP/ 2003) com Pós-Graduação em Saúde Coletiva, Nível de Especialização pela Faculdade 
Internacional de Curitiba (FACINTER - PR/ 2006) e Pós-Graduação Nível de Mestrado em Ciências da Saúde, Área de Concentração: Epidemiologia e Saúde Pública pela Universidade Federal do Amapá (UNIFAP - 2013). Atualmente desenvolve trabalhos junto ao Instituto de Pesquisas Científicas e Tecnológicas do Estado do Amapá - IEPA, trabalhando com Controle de Qualidade de Plantas Medicinais/Fitoterápicos e Práticas Integrativas e Complementares (FITOTERAPIA). Desenvolve atividades junto a Secretaria Municipal de Saúde de Macapá - PMM trabalhando com testagem de Infecções Sexualmente Transmissíveis. Desde 2007 é Docente Titular das Disciplinas de Bioquímica, Imunologia e Microbiologia do Curso de Bacharelado em Enfermagem da Faculdade Madre Tereza - Santana/AP. Atua em linhas de pesquisa direcionadas às Práticas Integrativas e Complementares (FITOTERAPIA) e Investigação de Doenças Emergentes, Reemergentes e Negligenciadas, com enfoque especial em Controle de Doenças Transmissíveis, Não Transmissíveis, Infecciosas e parasitárias de interesse médico-sanitário.

Camila Rodrigues Barbosa Nemer. Doutoranda em Saúde Pública pela ENSP/FIOCRUZ (2017-2021). Mestre pelo Programa de Pós Graduação da Universidade do Estado do Pará (PPGEnf - UEPA), bolsista CAPES. Graduada em enfermagem pela Universidade do Estado do Pará. Foi enfermeira da Estratégia da Saúde da Família, foi bolsista do Ministério da Saúde pelo Programa de Valorização do Profissional da Atenção Básica - PROVAB 2012/2013. Pertenceu ao Centro Acadêmico de Enfermagem/UEPA/Campus XII. Foi Bolsista de Iniciação Científica/FAPESPA/UEPA (2008 - 2009 e 2010 - 2011). Associada da Associação Brasileira de Enfermagem/Aben. Áreas de Interesse: Teoria das Representações Sociais, Enfermagem, Saúde da Família, Cuidar-Educar, Tecnologias educativas, Saúde do idoso/Saúde da mulher/Saúde do homem na atenção básica, HIV-AIDS, Vulnerabilidade socioambiental. Vice-presidente da ABen Seção Amapá (2016). Membro da Rede de Estudos de Tecnologias Educacionais (RETE). Membro do Grupo de Estudos em Doenças e Agravos Crônicos Transmissíveis e Não-transmissíveis - GEDAC. Membro do Grupo de pesquisa Vulnerabilidade Socioambiental, Desastres e Saúde.

Rubens Alex de Oliveira Menezes. Graduação em Enfermagem (Bacharelado e Licenciatura) pela Universidade Federal do Amapá (2009). Pós-Graduação em Microbiologia Nível de Especialização pela Universidade de Fortaleza, Pós-Graduação em Docência do Ensino Superior pela Faculdade de Tecnologia do Amapá - META, Pós-graduação em Gestão em saúde pública pela Faculdade de Macapá - FAMA, PósGraduação Nível de Mestrado em Ciências da Saúde Área de Concentração: Epidemiologia e Saúde Pública pela Universidade Federal do Amapá (2013). Pós-graduação Nível de Doutorado em Biologia de Agentes Infecciosos e Parasitários (PPG BAIP) pela Universidade Federal do Pará. Atualmente é docente do curso de enfermagem da Universidade Federal do Amapá (UNIFAP), Adjunto I, atuando na linha de pesquisa direcionada as doenças emergentes, reemergentes e negligenciadas, desenvolvendo estudos com enfoque especial em: Saúde pública e epidemiologia e controle de doenças transmissíveis, não transmissíveis, infecciosas e parasitárias de interesse médico-sanitário.

Como citar: Gonçalves, F.S., Sarges, R.M., Ramos, M.A., Souza, M.J.C, Nemer, CR.B., \& Menezes, R.A.O. 2020. Perfil clínico epidemiológico do câncer gástrico: revisão integrativa. Pubsaúde, 3, a041. DOI: https://dx.doi.org/10.31533/pubsaude3.a041

Recebido: 2 jun. 2020.

Revisado e aceito: 5 jun. 2020.

Conflito de interesse: os autores declaram, em relação aos produtos e companhias descritos nesse artigo, não ter interesses associativos, comerciais, de propriedade ou financeiros que representem conflito de interesse.

Licenciamento: Este artigo é publicado na modalidade Acesso Aberto sob a licença Creative Commons Atribuição 4.0 (CC-BY 4.0). 